\title{
Paragonimiasis and Renewed Crab-Eating Behavior in Six Communities from Two Ethnocultural Clusters in Southeastern Nigeria
}

\author{
Emmanuel Chukwunenye Uttah \\ Department of Biological Sciences, Cross River University of Technology, PMB 1123, Calabar, Cross River State, Nigeria \\ Correspondence should be addressed to Emmanuel Chukwunenye Uttah; drecuttah@yahoo.com
}

Received 15 August 2012; Accepted 9 September 2012

Academic Editors: H. Hisaeda, K. Peoc'H, and K. Sawanyawisuth

Copyright (C) 2013 Emmanuel Chukwunenye Uttah. This is an open access article distributed under the Creative Commons Attribution License, which permits unrestricted use, distribution, and reproduction in any medium, provided the original work is properly cited.

\begin{abstract}
This work was aimed at assessing the prevalence of paragonimiasis and crab-eating behavior in Southeastern Nigeria. Sputum examinations and questionnaire administration were carried out. Prevalence was $13.2 \%$ and was significantly higher among females $(14.6 \%)$ than males $(11.2 \%)(P<0.05)$. Overall, $77.2 \%$ of respondents across the communities eat crabs, and this was comparable between males $(76.4 \%)$ and females $(77.6 \%)(P>0.05)$. The prevalence was comparable between the two ethnocultural groups and between communities within each ethnocultural group $(P>0.05$ for both tests). The mean age of crab eaters was 43 years, while that of noncrab eaters was 26 years. Many (46.3\%) infected individuals presented low intensity infections (1-50 eggs/ova per $5 \mathrm{~mL}^{-1}$ sputum), while $28.8 \%$ and $23.8 \%$ presented moderate (51-100 eggs/ova per $5 \mathrm{~mL}^{-1}$ sputum) and high (above 100 eggs/ova per $5 \mathrm{~mL}^{-1}$ sputum) intensity infections, respectively. Infection risk among weekly eaters of crabs was 3 times higher than that of monthly eaters (OR 3.68), 19 times higher than that of quarterly eaters (OR 19.0), and 9 times higher than that of irregular eaters (OR 9.38). Concerted awareness campaign is needed to curb the renewed increase of the scourge in endemic Southeastern Nigeria.
\end{abstract}

\section{Introduction}

An estimated 22 million people are infected with paragonimiasis worldwide, and $10 \%$ of them live in Africa and Central and South America [1]. Paragonimiasis is one of the food-borne trematode (FBT) infections in humans, acquired following the consumption of raw or improperly cooked crabs or crayfish, containing infective metacercariae (cysts). According to Fried and Abruzzi [2], species of snail serve as the first intermediate host while local freshwater crustaceans (crabs and crayfish) serve as the second intermediate hosts, while humans and various mammals that feed on infected crustaceans are the definitive hosts of these lung flukes. In the host duodenum, the metacercariae excyst and penetrate the gut, and then the diaphragm, before migrating to the lung parenchyma. They develop into adult worms in cysts in the lungs. Here they lay eggs, which may be expectorated or swallowed and passed with stools, thus initiating a new cycle. The egg is an important diagnostic tool for detecting this trematode in the host, although other types of immunological and molecular detection tests are available [3].

Paragonimiasis is a neglected but reemerging zoonotic parasitic infection in Nigeria. It is now two and a half decades since endemic paragonimiasis was last reported in Southeastern Nigeria [4]. Endemic foci had been reported in Enugu and the areas around the Imo and Cross River, and their tributaries [5], Igwun River and River Iduma including Abam, Arochukwu, Bende, and Ohafia towns among others [4]. Our personal observations in some new foci in Eastern Nigeria have revealed massive eating of the crab species Sudanautes, which has been earlier confirmed as the intermediate host of Paragonimus uterobilateralis in Eastern Nigeria [4]. This work was therefore aimed at assessing the prevalence of paragonimiasis and crab-eating behavior among six communities in two main ethnocultural groups in Southeastern Nigeria. The specific objectives of the study include the following: (i) to ascertain the prevalence and intensities of vector infection in the six communities in 
Southeastern Nigeria; (ii) to determine the proportion of the population that eat crabs and how frequently they eat them; and (iii) to compare the results in (i) and (ii) above between the Igbo and Ikwerre ethnocultural groups that comprised the study area in Southeastern Nigeria.

\section{Materials and Methods}

2.1. The Study Areas. Six communities, comprising of three each from the two ethnocultural groups were studied in Southeastern Nigeria. The two main ethnocultural groups, were Ndi Igbo and Ikwerre groups. The three communities from the Ndi Igbo ethnocultural group were the Umulolo, Igwun River Basin, and Iduma River basin areas, which are located in the Imo River Basin, Igwun River Basin, and Iduma River Basin, respectively. These three communities are typically rural in setting and of monolithic population. They are mostly subsistent farmers, fishermen, artisans, traders, and significantly few white collar jobs. In these communities, crabs are caught by people in all categories of occupation for both subsistence and commercial purposes and sold both locally and in nearby towns. They are regarded as traditional delicacy.

The three study communities from the Ikwerre ethnocultural group were Oyigbo (located in the Imo River Basin), Choba, and Ogbakiri communities (both located in the New Calabar River Basin). These three communities are in the suburb of Port Harcourt, sprawling and highly populated and rapidly growing capital city of oil-rich Rivers State in the Niger Delta. Apart from the Ogbakiri that is rural in setting and of monolithic population, Choba and Oyigbo are urban and constituted predominantly of nonindigenes, and they could be described as assimilated into the Port Harcourt city. The population in these communities is constituted (in the reverse order to that of the Igbo ethnocultural communities) mostly of white collar jobbers, traders, artisans, fishermen, and lastly farmers. In these communities, crabs are caught by the indigenous Ikwerre people for both subsistence and economic purposes. The population here regards crab eating as delicacy to complement for both meat and fish as source of protein.

2.2. Studying Crab-Eating Behavior in the Study Area. All consenting persons from the study areas were helped to complete a structured questionnaire comprised of four questions bothering on personal biodata and on whether or not they did eat crabs. The questions were as follows: (1) Sex (male or female). (2) Age. (3) Do you eat crab? (yes or no). (4) How often do you eat crabs? (weekly, monthly, quarterly, yearly, or irregularly).

2.3. Examination for Paragonimus uterobilateralis. All consenting persons were provided with vials and asked to use them to provide their sputum. All the vials were collected from all consenting persons the following morning and brought to the laboratory. Sputum samples were examined for the presence of Paragonimus uterobilateralis eggs/ova to provide a diagnosis of paragonimiasis. To make up for the sensitivity concerns of sputum examination for detection of eggs, seven sputum examinations per person were carried out as recommended [1]. The estimated sensitivity, specificity, and positive and negative predictive values of sputum sampling in the area were calculated to be $0.60,0.63,0.13$, and 0.97, respectively. All individuals found to have eggs in their sputum were treated with praziquantel at a dose of $3 \times 25$ $\mathrm{mg} / \mathrm{kg}$ of body weight per day for 3 consecutive days [6].

2.4. Ethical Clearance. Ethical approval for the study was received from the Cross River University of Technology Ethical Committee. Additionally, ethical clearance was obtained from the Ministry of Health in the five respective Local Government Areas, which are the Bende LGA in Abia State, the Okigwe LGA in Imo State, and the Oyigbo, Obio/Akpor, and Emohua LGAs in Rivers State.

2.5. Data Analysis. The Epi Info version 6.0 was used in entering data, and SPSS for windows (1995 version) was used for data analysis. The geometric mean intensity (GMI) of eggs/ova was calculated as antilog $\left(\sum \log (x+1) / n\right)$, with $x$ being the egg/ova counts per $5 \mathrm{~mL}$ of sputum in infected individuals and $n$ the number of infected individuals examined. Proportions were compared by chi-square $\left(\chi^{2}\right)$ or Fisher's exact test and relative risks of infection by odds ratio (OR).

\section{Results}

3.1. Prevalence of Human Infection. A total of 604 consenting individuals provided sputum samples in the study, comprising $242(40.1 \%)$ males and $362(59.9 \%)$ females. Of these $80(13.2 \%)$ were found infected with $P$. uterobilateralis. The prevalence of infection was $11.2 \%$ (27) for men and $14.6 \%$ (53) for women, and the difference was significant $(P<0.05)$. The prevalence of paragonimiasis among the communities ranged from $10.1 \%$ in Choba to $17.4 \%$ in Umulolo Okigwe (see Table 1), and there was no evidence of significant difference between the communities $(P>0.05)$.

3.2. Assessment of Human Infection in relation to Crab Eating among Respondents. The distribution of prevalence of infection and the crab-eating behavior among the various communities is also shown in Table 1. Overall, 77.2\% (466) of respondents across the various communities eat crabs, and this was comparable between males $(n=185 ; 76.4 \%)$ and females $(n=281 ; 77.6 \%)(P>0.05)$. Crab eating among the communities ranged from $66.9 \%$ in Oyigbo to $91.5 \%$ in Ogbakiri. The prevalence was comparable between both the two ethnocultural groups and between communities within each ethnocultural group ( $P>0.05$ for both tests).

The comparison between crab-eating and non-crabeating categories showed that three-quarter of crab eaters were females (see Table 2). The mean age of crab eaters was 43 years, while that of noncrab eaters was 26 years.

3.3. Intensity of Infection. The frequency distribution of intensities of infection is summarized in Table 3. Egg counts 
TABLE 1: Prevalence of $P$. uterobilateralis infection and crab-eating behavior among the various localities.

\begin{tabular}{lccc}
\hline Locality & No. examined & No. positive (\%) & No. crab eating (\%) \\
\hline Igwun River Basin & 118 & $15(12.7)$ & $97(82.2)$ \\
Iduma River Basin & 93 & $14(15.1)$ & $71(76.3)$ \\
Imo River (Umulolo) & 86 & $15(17.4)$ & $70(81.4)$ \\
Imo River (Oyigbo) & 127 & $13(10.2)$ & $85(66.9)$ \\
New Cal. River (Choba) & 109 & $11(10.1)$ & $78(71.6)$ \\
New Cal. River (Ogbakiri) & 71 & $12(16.9)$ & $65(91.5)$ \\
\hline Total & 604 & $80(13.2)$ & $466(77.2)$ \\
\hline
\end{tabular}

TABLE 2: Comparison of some epidemiological indices of crab eaters and noncrab eaters in Southeastern Nigeria.

\begin{tabular}{lccc}
\hline & Crab eating & Noncrab eating & Statistical difference \\
\hline Number examined & 466 & 138 & - \\
Those infected (\%) & $80(17.2)$ & $0(0)$ & $\chi^{2}=25.839(P>0.05)$ \\
Mean intensity & 83 & 0 & - \\
Sex ratio (M:F) & $1: 3$ & $1: 2$ & - \\
Mean age (years) & 43 & 26 & $\chi^{2}=19.02(P>0.05)$ \\
\hline
\end{tabular}

of 1-50 eggs/ova per $5 \mathrm{~mL}^{-1}$ sputum, 51-100 eggs/ova per $5 \mathrm{~mL}^{-1}$ sputum, and above 100 eggs/ova per $5 \mathrm{~mL}^{-1}$ were regarded as low, moderate, and high intensities, respectively. Based on this categorization, $46.3 \%$ of infected individuals presented low intensity infections as against $28.8 \%$ and $23.8 \%$ who presented with moderate and high intensity infections, respectively.

3.4. Regularity of Crab Eating. The prevalence of paragonimiasis infection increased with increasing frequency of crab eating as shown in Table 4. The risk of paragonimiasis infection among those who ate crabs weekly was 3 times higher than among those who ate monthly (OR 3.68), 19 times higher than among those who ate quarterly (OR 19.0), and 9 times than among irregular eaters (OR 9.38). The risk of being infected among those who ate crabs irregularly was twice of those who ate crabs quarterly (OR 1.95).

\section{Discussion}

Paragonimus species are extremely successful parasites and are widely geographically distributed. They are found in tropical, subtropical, and temperate climates [7]. More recently, it has been estimated that 293 million people are at risk, whereas several million are actually infected [3, 8]. Geographic regions that have or have had a high prevalence of disease include Cameroon, which is contiguous to Southeastern Nigeria. However, environmental factors, such as pollution, adversely affect the population of either the first (freshwater snail) or second (freshwater crustacean) intermediate host and hence consequently affect the prevalence of the disease [7].

The prevalence of $P$. uterobilateralis in this study was relatively higher than that reported in study among pupils in Southwestern Cameroon [9], but comparable to that of another study on persons of all ages in the same Southeastern
Cameroon [6]. Prevalence of infection could be higher but for the suboptimal sensitivities of the use of eggs/ova in sputum [10], compared to the good sensitivity and specificity of the ELISA method, especially ELISA using partially purified cysteine proteinases method $[6,11]$. However, the repeated sputum examinations per person adopted in this study are known to improve the sensitivity of the parasitological method [1]. Another limitation in this study is that the parasitological method of egg/ova detection in sputum cannot detect those in the pre-patent period of infection or extrapulmonary paragonimiasis [12].

The prevalence in this study was significantly higher in women. This is expected as a significantly higher proportion of crab eaters in the study area were females; only one-quarter were males. However, prevalence was comparable between both sexes in neighboring southwest area of Cameroon [9]. Many other researchers have reported no sex-related difference in prevalence $[13,14]$. In contrast Singh and coworkers reported a higher prevalence among male patients in Manipur, India [15]. However, paragonimiasis is found in children, adults, and all categories of people [14]. On the whole, crab eating is common in Eastern Nigeria. It is quite popular and comparable in all the communities in the two major ethnocultural groups. However, the mean age of crab eaters is older (43 years) than that of noncrab eaters ( 26 years), indicating that crab eating is not as popular among the younger persons in Eastern Nigeria as among the older ones. This is encouraging as it would lower the risk of paragonimiasis infection over time.

Presently, the high popularity of crab eating explains the relatively high prevalence of paragonimiasis in Eastern Nigeria. More than a fifth of infected persons presented high intensities of egg/ova in sputum, while almost half of the infected persons presented low intensities. This in addition to the relatively high prevalence of infection buttresses the status of Eastern Nigeria as a paragonimiasis endemic area. 
TABLE 3: Frequency distribution of Paragonimus egg counts in various localities.

\begin{tabular}{lccccccc}
\hline & \multicolumn{7}{c}{ No. (\%) of persons with different egg/ova counts $5 \mathrm{~mL}^{-1}$ sputum } \\
Locality & No. examined & No. +ve (\%) & $1-50$ & $51-100$ & $101-150$ & $151-200$ & $200+$ \\
\hline Igwun Basin & 118 & $15(12.7)$ & $8(53.3)$ & $4(26.7)$ & $2(13.3)$ & $1(6.7)$ & $0(0)$ \\
Iduma Basin & 93 & $14(15.1)$ & $6(42.9)$ & $5(35.7)$ & $1(7.1)$ & $1(7.1)$ & $1(7.1)$ \\
Imo River (Umulolo) & 86 & $15(17.4)$ & $9(60.0)$ & $3(20.0)$ & $2(13.3)$ & $1(6.7)$ & $0(0)$ \\
Imo River (Oyigbo) & 127 & $13(10.2)$ & $4(30.8)$ & $3(23.1)$ & $2(15.4)$ & $2(15.4)$ & $2(15.4)$ \\
Imo River (Choba) & 109 & $11(10.1)$ & $5(45.5)$ & $5(45.5)$ & $1(9.1)$ & $0(0)$ & $0(0)$ \\
Imo River (Ogbakiri) & 71 & $12(16.9)$ & $5(41.5)$ & $3(25.0)$ & $2(16.7)$ & $1(8.3)$ & $1(8.3)$ \\
\hline Total & 604 & $80(13.2)$ & $37(46.3)$ & $23(28.7)$ & $10(12.5)$ & $6(7.5)$ & $4(5.0)$ \\
\hline
\end{tabular}

TABLE 4: Relationship between paragonimiasis infection and frequency of crab eating in some communities in Southeastern Nigeria.

\begin{tabular}{lccc}
\hline Frequency & No. crab eating & No. infected & Prevalence (\%) \\
\hline Weekly & 93 & 38 & 40.9 \\
Monthly & 209 & 33 & 15.8 \\
Quarterly & 57 & 2 & 3.5 \\
Yearly & 5 & 0 & 0.0 \\
Irregular & 102 & 7 & 6.9 \\
\hline Total & 466 & 80 & 17.2 \\
\hline
\end{tabular}

The higher the frequency of crab eating, the higher the risk of infection with paragonimiasis. Committed eaters such as weekly eaters had greater risk of being infected than monthly or yearly eaters. Surprisingly, the risk of infection was higher among irregular eaters than that of quarterly eaters. The reasons for this are not readily known. However, quarterly and yearly eaters could be regarded as curious or circumstantial eaters, while some of the irregular eaters could be incidental eaters who may eat more frequently at a time and less frequently at other times.

The frequency for some food-borne parasitic diseases is generally on the increase $[16,17]$. Several of these may be directly linked to the dramatic increase in aquaculture, and they demonstrate how subtle changes in ecology, which may be economically driven, may contribute to an increased incidence of parasitic diseases [8].

Paragonimiasis is not popular among health policy makers in Southeastern Nigeria, probably because it causes very limited morbidity and with only occasional deaths. It has been called "benign endemic hemoptysis" [7]. Many patients are asymptomatic or have subclinical disease and are unaware of the infection, whereas others have mild-tomoderate symptoms for many years before they come to medical attention, if they ever come to medical attention at all [18]. Regardless of the mild nature of paragonimiasis in many patients, it remains an important cause of morbidity in many parts of the world [7] and therefore should come into focus in health policy thrusts in endemic areas. This has become necessary because of incessant loss of man hours as a consequence of the scourge in Southeastern Nigeria. Common complaints are associated with the scourge that result in loss of man hours include fever, chest pain, dyspnea, fatigue and urticaria, eosinophilia, diarrhea, gastroenteritis, in the early phases of the infection; and cough and recurrent hemoptysis in the chronic stage of the infection. Furthermore, the migrating worms may cause bronchiectasis, interstitial pneumonitis, transient hemorrhage, or bronchopneumonia to varying degrees $[19,20]$.

The implication of high prevalence of paragonimiasis in Southeastern Nigeria is its overlap with tuberculosis [21] and its consequent diagnostic confusion. The existence of another Paragonimus species, especially $P$. africanus, is most probable as southeastern is contiguous with Southwestern Cameroon, an area where the latter is predominant [6]. With a preponderance of unqualified personnel, and ill-equipped diagnostic laboratories, the problems of wrong diagnosis especially of tuberculosis would likely escalate. So many false positives would be subjected to the rigors of strong medications that could further complicate their health statuses by causing side effects and/or experiencing drug interactions $[15,22]$. This informs the need to intensify awareness campaign in the epidemiology, clinical manifestations, and control of paragonimiasis in Southeastern Nigeria, especially on the dangers of eating improperly cooked crabs and crayfishes.

Substantially reduction in infections in countries that traditionally have had high incidences of infection has been directly related to educational efforts [3]. Therefore, mass education and awareness campaign to provoke changes in customs and food preparation practices should be emphasized in Southeastern Nigeria. The epidemiology and economic importance of paragonimiasis should be explained in such a way that majority of the people would be adequately informed about the risks of their food choices and food preparation preferences [7].

\section{Conflict of Interests}

The author declares that he has no conflict of interests.

\section{Acknowledgments}

The author thanks the health authorities of Bende, Okigwe, Oyigbo, Obio/Akpor, and Emohua Local Government Areas and the town heads of the respective communities that made up the study area for their assistance in creating awareness in their areas for the study. 


\section{References}

[1] C. Toscano, Y. S. Hai, and K. E. Mott, "Paragonimiasis and tuberculosis, diagnostic confusion: a review of literature," Tropical Diseases Bulletin, vol. 92, no. 2, pp. R1-R27, 1995.

[2] B. Fried and A. Abruzzi, "Food-borne trematode infections of humans in the United States of America," Parasitology Research, vol. 106, no. 6, pp. 1263-1280, 2010.

[3] D. Blair, T. Agatsuma, and W. Wang, "Paragonimiasis," in FoodBorne Parasitic Zoonoses, K. D. Murrell and B. Fried, Eds., vol. 11, pp. 117-150, Springer, New York, NY, USA, 2008.

[4] J. K. Udonsi, "Endemic Paragonimus infection in upper Igwun Basin, Nigeria: a preliminary report on a renewed outbreak," Annals of Tropical Medicine and Parasitology, vol. 81, no. 1, pp. 57-62, 1987.

[5] C. Nwokolo, "Outbreak of paragonimiasis in Eastern Nigeria," The Lancet, vol. 1, no. 7740, pp. 32-33, 1972.

[6] A. Nkouawa, M. Okamoto, A. K. Mabou et al., "Paragonimiasis in Cameroon: molecular identification, serodiagnosis and clinical manifestations," Transactions of the Royal Society of Tropical Medicine and Hygiene, vol. 103, no. 3, pp. 255-261, 2009.

[7] G. W. Procop, "North American paragonimiasis (caused by $\mathrm{Pa}$ ragonimus kellicotti) in the context of global paragonimiasis," Clinical Microbiology Reviews, vol. 22, no. 3, pp. 415-446, 2009.

[8] J. Keiser and J. Utzinger, "Emerging foodborne trematodiasis," Emerging Infectious Diseases, vol. 11, no. 10, pp. 1507-1514, 2005.

[9] R. Moyou-Somo and D. Tagni-Zukam, "Paragonimiasis in Cameroon: clinicoradiologic features and outcome of treatment," Medecine Tropicale, vol. 63, no. 2, pp. 163-167, 2003.

[10] S. Vidamaly, K. Choumlivong, V. Keolouangkhot, N. Vannavong, J. Kanpittaya, and M. Strobel, "Paragonimiasis: a common cause of persistent pleural effusion in Lao PDR," Transactions of the Royal Society of Tropical Medicine and Hygiene, vol. 103, no. 10, pp. 1019-1023, 2009.

[11] T. Ikeda, Y. Oikawa, and T. Nishiyama, "Enzyme-linked immunosorbent assay using cysteine proteinase antigens for immunodiagnosis of human paragonimiasis," American Journal of Tropical Medicine and Hygiene, vol. 55, no. 4, pp. 434-437, 1996.

[12] R. C. Mahajan, "Paragonimiasis: an emerging public health problem in India," Indian Journal of Medical Research, vol. 121, no. 6, pp. 716-718, 2005.

[13] F. Uchiyama, Y. Morimoto, and Y. Nawa, "Re-emergence of paragonimiasis in Kyushu, Japan," Southeast Asian Journal of Tropical Medicine and Public Health, vol. 30, no. 4, pp. 686-691, 1999.

[14] J. I. Ashitani, K. Kumamoto, and S. Matsukura, "Paragonimiasis westermani with multifocal lesions in lungs and skin," Internal Medicine, vol. 39, no. 5, pp. 433-436, 2000.

[15] T. S. Singh, S. S. Mutum, and M. A. Razaque, "Pulmonary paragonimiasis: clinical features, diagnosis and treatment of 39 cases in Manipur," Transactions of the Royal Society of Tropical Medicine and Hygiene, vol. 80, no. 6, pp. 967-971, 1986.

[16] H. Maruyama, S. Noda, and Y. Nawa, "Emerging problems of parasitic disease in southern Kyushu, Japan," Japanese Journal of Parasitology, vol. 45, no. 3, pp. 192-200, 1996.

[17] Y. Nawa, "Re-emergence of paragonimiasis," Internal Medicine, vol. 39, no. 5, pp. 353-354, 2000.

[18] D. M. Boé and M. I. Schwarz, "A 31-year-old man with chronic cough and hemoptysis," Chest, vol. 132, no. 2, pp. 721-726, 2007.
[19] F. T. Kagawa, "Pulmonary paragonimiasis," Seminars in Respiratory Infections, vol. 12, no. 2, pp. 149-158, 1997.

[20] A. Nana and S. Bovornkitti, "Pleuropulmonary paragonimiasis," Seminars in Respiratory Medicine, vol. 12, no. 1, pp. 46-54, 1991.

[21] K. Narain, K. R. Devi, and J. Mahanta, "Pulmonary paragonimiasis and smear-negative pulmonary tuberculosis: a diagnostic dilemma," International Journal of Tuberculosis and Lung Disease, vol. 8, no. 5, pp. 621-622, 2004.

[22] J. R. Johnson, A. Falk, C. Iber, and S. Davies, "Paragonimiasis in the United States. A report of nine cases in Hmong immigrants," Chest, vol. 82, no. 2, pp. 168-171, 1982. 


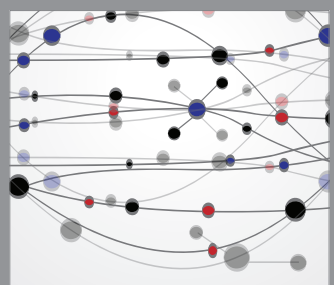

The Scientific World Journal
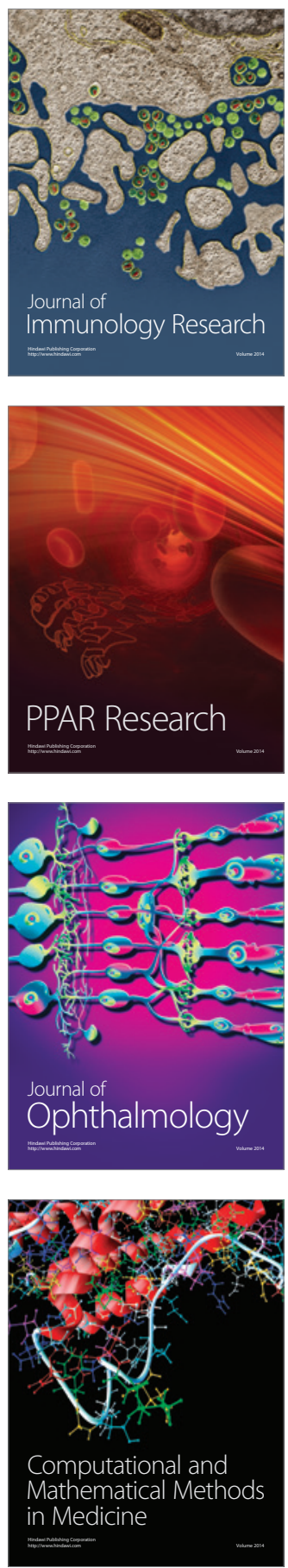

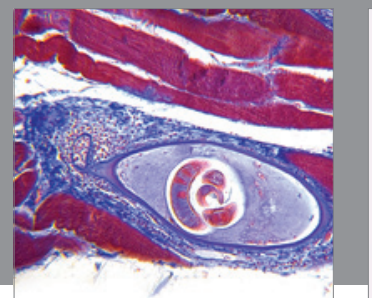

Gastroenterology

Research and Practice
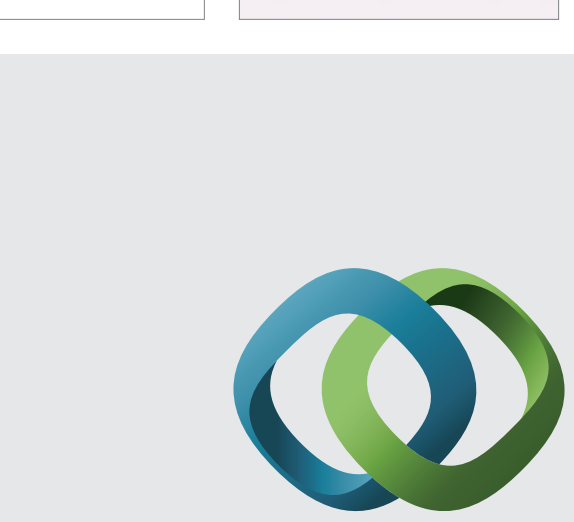

\section{Hindawi}

Submit your manuscripts at

http://www.hindawi.com
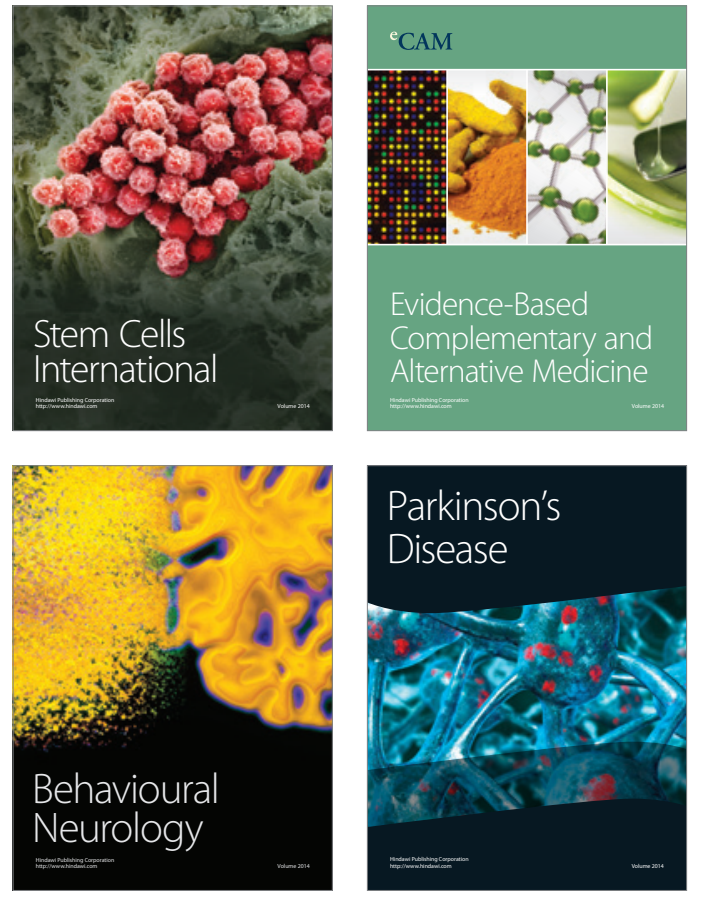
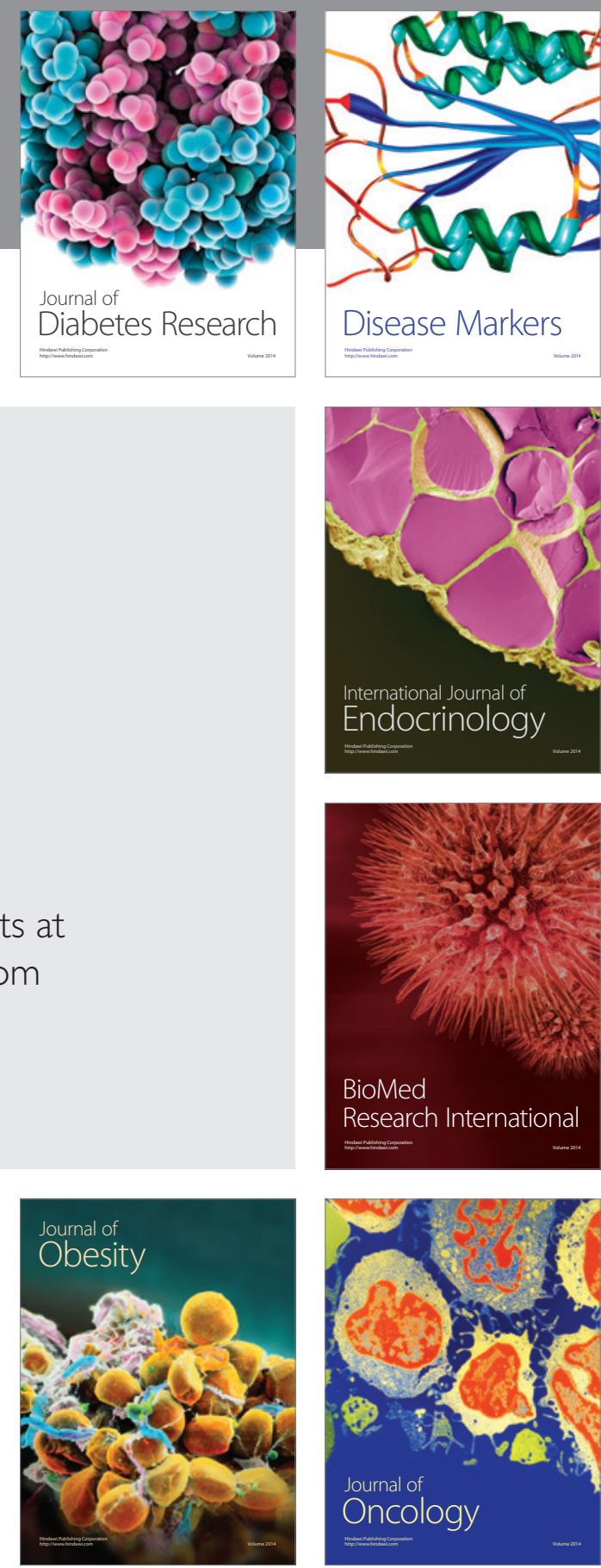

Disease Markers
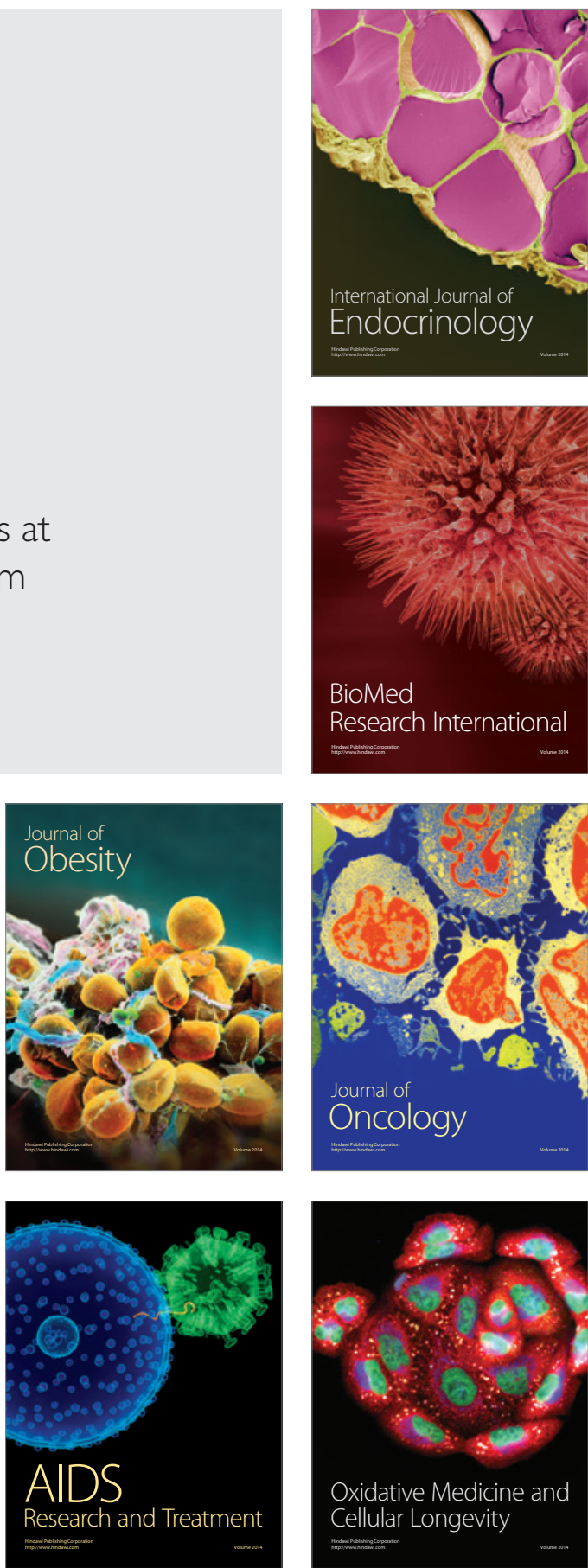